\title{
Sobre los desafíos de la filosofía del derecho en la era del poder
}

\author{
On the challenges of Philosophy of Law in the age of power
}

\author{
Camila Herrera PARdo \\ Facultad de Derecho y Ciencias Políticas de la Universidad de La Sabana \\ https://orcid.org/0000-0001-6018-6167 \\ camila.herrera@unisabana.edu.co
}

RECIBIDO: 08/05/2018 / ACEPTADO: 31/10/2019

Resumen: El presente artículo propone examinar las múltiples maneras en que la exacerbación de la intensidad del poder humano en la era presenta y la ruptura de límites fácticos, antes considerados incontrovertibles, plantea una serie de problemas a la Filosofía del Derecho, que no pueden ser superados sin una radical revisión de los fundamentos metafísicos, gnoseológicos y antropológicos sobre los que se ha construido la comprensión moderna del orden jurídico.

Palabras clave: Filosofía del Derecho, Naturaleza, Derecho Natural, Iusnaturalismo, Metafísica, Posthumanismo, Evolución.
Abstract: This article examines the various ways in which the exacerbation of human power in the «present age» and the breaking of factual limits, formerly considered incontrovertible, raises a number of problems to Legal Philosophy, which cannot be overcome without a radical revision of the metaphysical, gnoseological and anthropological foundations of the modern understanding of the juridical order.

Keywords: Philosophy of Law, nature, Natural Law tradition, Natural Law, Metaphysics, Posthumanism, evolution.

Sumario:INTRODUCCIÓN. 1. PUNTO DE PARTIDA: DEFINICIONES Y OBSERVACIONES. 1.1. La Filosofía del Derecho y el paradigma iusfilosófico moderno. 1.2. La «era del poder». 2. La Filosofía del derecho y el eclipse de la razón. 3. RELATIVIZACIÓN DE LA NATURALEZA. 3.1. La relativización de los límites fácticos. 4. DEL UNIVOCISMO A LA DISOLUCIÓN DEL LÍMITE. 5. UNIVOCIDAD O EQUIVOCIDAD DEL DERECHO Y MONISMO EN LA PREDICACIÓN DEL DOMINIO. 6. EN LUGAR DE CONCLUSIONES... UNA PREGUNTA ABIERTA. BIBLIOGRAFÍA.

\section{INTRODUCCIÓN}

E n las líneas que siguen se esbozarán las razones por las cuales parece plausible la afirmación de que la Filosofía del Derecho deberá enfrentarse en un futuro próximo a aporías insolubles si no somete a una revisión profunda algunos de sus postulados fundamentales y sus presupuestos metafísicos. $\mathrm{O}$, lo que es lo mismo, las razones por las cuales, cabe pensar que el sector dominante de la iusfilosofía contemporánea puede perder su capacidad legitimadora y fun-

* La autora agradece a los profesores José Julián Suárez Rodríguez, Luciano Damián Laise, Martha Miranda Novoa, Alpiniano García y Fabio Enrique Pulido, quienes con su abierto y amistoso diálogo orientaron estas reflexiones. 
damentadora, así como su función crítica respecto de formas reales y efectivas de injusticia que, dado el aumento de la intensidad del poder humano, pueden llegar a ser inéditas.

Se sostendrá que, contrariamente a pretensiones de «neutralidad metafísica» comúnmente aceptadas desde la proclamación del célebre «etiamsi daremus» ${ }^{1}$, la Filosofía del Derecho no puede ser indiferente frente a cuestiones como las de la participación, la racionalidad intrínseca del mundo o la existencia de un plano metafenoménico en la realidad, así como que las posiciones voluntaristas y nominalistas, predominantes tanto en la modernidad como en la premodernidad no occidental, contienen en sí el germen de insalvables problemas de fundamentación y coherencia. Por otra parte, se llamará la atención sobre lo cuestionables que son las asunciones centrales del sector mayoritario de la doctrina sobre la naturaleza del derecho las cuales, además de ser exclusivas de un periodo que, desde la adecuada perspectiva histórica es realmente breve, necesariamente desembocan en una visión conflictual de lo jurídico, así como en contradicciones que se podrían evitar adoptando una noción más amplia del derecho.

\section{PUNTO DE PARTIDA: DEFINICIONES Y OBSERVACIONES}

\subsection{La Filosofía del Derecho y el paradigma iusfilosófico moderno}

El primer presupuesto para la demostración de lo recién enunciado consiste en la acotación del significado de sus términos fundamentales. Para ello no habrá otra opción que acudir a definiciones estipulativas, toda vez que la discusión sobre lo que es esencialmente la filosofía o sobre los elementos definitorios de la modernidad exigiría en sí misma otro tipo de reflexión, mucho más extensa ${ }^{2}$. Así pues, a los efectos de este estudio, la expresión «Filosofía del Derecho» se empleará en sentido estricto para designar la actividad especulativa -no por ello desprovista de función y necesidad práctica- que, en

1 Grocio, H., De iure belli ac pacis, Proelegomena, N. 9. Sobre la hipótesis «Etiamsi Daremus», cfr. Hervada, J., «Lo nuevo y lo viejo en la hipótesis etiamsi daremus de Grocio», Revista de Estudios Histórico-furídicos, VII (1982), pp. 351 y ss.; cfr. también RodRíGUEZ-MOLINERO, M., «La doctrina del derecho natural de Hugo Grocio en los albores del pensamiento moderno», Persona y Derecho, vol. 26 (1992), pp. 291-305.

2 Cfr. Hervada, J., Lecciones Propedéuticas de Filosofía del Derecho, Pamplona, 2000, pp. 17-56; MarTínez Doral, J.M., La estructura del conocimiento jurídico, Eunsa, Pamplona, 1963. 
primer término, busca establecer qué es el derecho (quid ius), a la luz de sus últimas causas (cuestión ontológica) y, asimismo, se ocupa de los problemas relativos a su conocimiento (cuestión gnoseológica y epistemológica) y de los valores o bienes que el orden jurídico salvaguarda (cuestión axiológica). Dicho saber, aunque especulativo y, por tanto, no subordinado a una finalidad práctica, cumple, como se señaló anteriormente, una función fundamentadora y crítica respecto del oficio del jurista, ya que el quid iuris es irresoluble con prescindencia de la reflexión previa sobre el quid ius ${ }^{3}$, amén de que sin la luz de una reflexión sobre la esencia de lo jurídico resulta imposible distinguir entre el verdadero derecho y la simple fuerza recubierta del ropaje de la juridicidad; la norma legítima de la amenaza de los bandidos, o el oficio del jurista de un refinado sicariato ${ }^{4}$ que, en lugar de armas, acude a la retórica y a las instituciones jurídicas.

En sentido lato, sin embargo, se entenderá por Filosofía del Derecho aquello que en el mundo académico se reconoce como tal y, por lo tanto, la reflexión que no está directamente dirigida a la solución de problemas jurídicos a la luz del derecho vigente, o a la descripción de instituciones específicas de una rama del derecho (v.gr. propiedad, contrato), sino que define y explica, en un mayor nivel de abstracción, aspectos fundamentales del fenómeno jurídico. En este sentido, se llamará Filosofía del Derecho a un entramado de saberes y cuestiones, que en muchos casos no se diferencia adecuadamente de la misma ciencia jurídica en el plano más alto de teorización.

Por otra parte, se entenderá por «paradigma moderno de la Filosofía jurídica» el variopinto conjunto de doctrinas que coinciden en definir dualmente al derecho, en términos disyuntivos de norma o facultad. Es decir, que parten del supuesto incontrovertible de que los sujetos están dotados -por naturaleza, concesión o convención- de una serie de poderes que, cuando re-

3 Cfr. Herrera Jaramillo, F.J., Filosofía del Derecho, Ediciones Universidad Javeriana, Bogotá, 1996, p. 51.

4 La comparación de la práctica del derecho con el oficio del mercenario no es, en modo alguno, novedosa. Así, por ejemplo, en 1979 el conocido abogado corporativo Martin Lipton llegó a afirmar en una revista de difusión mundial: «corporate takeovers are analogous to feudal wars, and the lawyers are the mercenaries» (cfr. LIPTON, M., «Business: Those guns for hire», Time Magazine (Jan 29, 1979). Esta «confesión» resulta significativamente concordante con la acusación que, desde una postura ideológica diametralmente distinta, formulara Harold Laski contra los abogados corporativos a quienes llegó a llamar «the essential mercenaries of the propertied class» (cfr. LASKI, H.J., The American Democracy: A Commentary and An Interpretation, Viking Press, New York, 1948, p. 591). 
caen sobre bienes externos se llaman propiedad y cuando se enfocan como operaciones -con cierto grado de transitividad- se llaman libertades. Estos poderes que, según la opinión predominante de la teoría jurídica moderna, se llaman «derechos» 0 «derechos subjetivos», están limitados fácticamente por circunstancias como la abundancia o la escasez, la posibilidad física, o la existencia de fuerzas sociales opuestas, y jurídicamente, por las normas, las cuales, se denominan, generalmente «Derecho» 0 «derecho objetivo». Con distinta intensidad, la historia de la moderna Filosofía y Teoría del Derecho consiste en un análisis de las maneras en las que las normas direccionan y limitan los poderes subjetivos. Así, por ejemplo, se detienen en la interpretación de cuándo y en qué circunstancias la norma puede motivar y moldear la conducta de modo válido y legítimo, escrutan rigurosamente la estructura lógica de la norma jurídica, indagan si esta es o no distinguible de otros fenómenos normativos y cuál es la organización del universo normativo. Cuestiones que en apariencia son tan diversas como la legitimidad de la discrecionalidad judicial, la distinción entre la norma jurídica y la norma moral o la estructura lógica abierta o cerrada de las reglas y principios al final se resumen en esta única cuestión medular: ¿cómo es que la norma determina positiva o negativamente la libertad humana? Ahora bien, en tanto que esta pregunta, en la que confluyen la práctica totalidad de teorías y filosofías jurídicas contemporáneas, no tiene que ver tanto con el quid ius -que aparece como precondición implícitacomo con la descripción de los mecanismos de operación de norma y libertad, parece plausible la aserción de que en la Filosofía jurídica actual es realmente indistinta de otras disciplinas de carácter más fenoménico o científico, como la teoría del derecho y la sociología jurídica. Esto, por supuesto, con los debidos matices y exclusiones.

Como se puede intuir, a pesar de la coincidencia en los presupuestos -el derecho es norma y libertad o si se quiere norma y poder-y en la cuestión central sobre su mutua interacción, existe en la filosofía-teoría jurídica una gran variedad de enfoques y de respuestas. Así, por ejemplo, existen perspectivas que se interesan principalmente por las cuestiones relativas a la significación de la norma y la cognoscibilidad de sus mandatos, mientras que otros enfoques estarán centrados en descubrir los juegos de poder que subyacen en los procesos de formulación normativa y denuncian la arbitraria forma en que esta coarta desigualmente las libertades. Algunos enfoques insistirán en una forma típicamente jurídica de moldear la libertad, en tanto que otros insisten en la tesis contraria y resaltan la unidad de fondo de todos los ámbitos normativos. También se distinguen paradigmas que enfatizan la primacía de las libertades 
y exigen que la norma de origen humano tenga, al menos parcialmente, su anclaje en exigencias prepositivas, mientras que otras encuentran suficiente explicación de la juridicidad en el simple acto de poder. Sin embargo, se insiste, el hecho de la coincidencia fundamental en la cuestión del quid ius, es suficiente para englobar a tan diversa pluralidad de doctrina en una gran categoría, contrapuesta, por otra parte, a lo que se podría llamar «modelo iusfilosófico clásico»o «realismo jurídico clásico». Este último está caracterizado por una definición analógica $-\mathrm{y}$ no dual o disyuntiva- del derecho en la que el punto de gravitación es la ipsa res iusta, esto es, la misma cosa justa. Cosa concreta y limitada, debida y exigida, por ser suya de alguien y que, analizada desde la perspectiva de la acción de dominio, se vincula al elemento de poder o libertad y vista desde la perspectiva de la ratio que delimita al objeto se vincula al elemento normativo 5 .

Tan importante como la definición del derecho en términos de norma y/o facultad, es la pretensión arquetípicamente moderna de definir las cuestiones jurídicas fundamentales con prescindencia de una reflexión metafísica o teológica. La Filosofía del Derecho moderna es heredera legítima del programa grociano $^{6}$ de explicar el fenómeno jurídico como si Dios no existiera, pretensión que en su época parecía necesaria dada la aparente imposibilidad de llegar a un acuerdo sobre verdades teológicas y las exigencias de la convivencia. Ello no quiere decir, que se trate de programas necesariamente ateos, o incluso,

5 Cfr. Hervada, J., Lecciones Propedéuticas de Filosofía del Derecho, cit, pp. 71-240; ID., ¿Qué es el Derecho?. La moderna respuesta del realismo jurídico, Eunsa, Pamplona, 2002; MASsinI, C.I., Filosofía del Derecho. vol.1. El derecho natural y los derechos humanos, Lexis-Nexis, Buenos Aires, 2005, pp. 31-50; Schouppe, J.P., Le realisme juridique, Story-Scientia, Bruxelles, 1987; RabBI-BaLDI, R., «El concepto de Derecho en el realismo clásico a partir de las opiniones de Michel Villey y Georges Kalinowski», Persona y derecho, n 25 (1991), pp. 73-114.

6 Este programa, que históricamente se resume bajo el rótulo de «hipótesis etiamsi daremus», no es una novedad absoluta de Grocio en tanto que ya varios autores escolásticos habían expresado con anterioridad la posibilidad de conocer las verdades fundamentales de la ley natural a partir de la simple consideración de la naturaleza objetiva de las cosas, de donde se colige que se trata de conclusiones de cierta manera accesibles incluso en el supuesto de que Dios no existiera pero la naturaleza conservara su estructura. Empero, todos los predecesores de Grocio, al tratar de la hipótesis en cuestión, precisaban que si bien tenía validez como ejercicio de pensamiento, se trataba de una afirmación falsa e imposible. Ello en la medida en que, desde las coordenadas teóricas del principio de participación resulta imposible sostener la existencia de un plano óntico que se sustente a sí mismo. Grocio, en cambio, al plantear la hipótesis la califica únicamente de falsa. Por lo tanto, rompe la subordinación ontológica entre los planos del ser por participación y el Ser pleno. (Cfr. Hervada, J., «Lo nuevo y lo viejo en la hipótesis 'etiamsi daremus' de Grocio», cit.). 
que nieguen que, en último término, otra configuración cósmica daría lugar a otros principios y otras exigencias jurídicas. Lo único que quiere decir es que, en el plano del conocimiento, existe una cierta pretensión de autonomía del conocimiento sobre los fundamentos del derecho y de las verdades prácticas fundamentales, por lo el discurso iusfilosófico puede subsistir con independencia del colapso de los saberes más radicales de la metafísica y la teología.

\subsection{La «era del poder»}

Junto a la definición de Filosofía del Derecho expuesta hasta el momento, el presente ensayo parte del supuesto de que la «hora presente» plantea ciertos desafíos hasta ahora inéditos, que la Filosofía del Derecho ha de afrontar. Si, en parte, la Filosofía del Derecho procura la justificar la primacía de la razón jurídica sobre el poder puro (y no solamente la conservación de la razón en su aspecto más servil e instrumental), dicha función ha de entenderse especialmente relevante en una era en la que el poder humano ha alcanzado dimensiones sin precedentes. Más que en ninguna otra época, la tecnología parece disolver las barreras de lo que antes parecía imposible. Los aspectos más cotidianos de la vida contemporánea son logros sobre lo impensable o lo inaudito. Las últimas revoluciones en el transporte y la comunicación han relativizado, en cierto modo, las barreras del tiempo y del espacio ${ }^{7}$, creando la era de la inmediatez y la hipercomunicación. La información y el conocimiento son accesibles en una escala e intensidad inimaginable hace décadas. También el poderío económico y militar se resisten a cualquier comparación histórica. La era nuclear ha traído consigo el crecimiento exponencial del potencial destructivo de la guerra, hasta el punto de que la amenaza real de aniquilación masiva ha sido, para algunos, el elemento principal de contención frente a una nueva guerra mundial y ha moldeado la dinámica de las relaciones internacionales desde la segunda posguerra del siglo $\mathrm{XX}^{8}$. Incluso ideas como la reconfiguración biológica de la especie ${ }^{9}$,

7 Harvey, D., The Condition of Postmodernity: An Enquiry into the Origins of Cultural Change, Blackwell, Cambridge, MA, 1990, pp. 201 a 240; BAUMAN, Z., La globalización. Consecuencias humanas, Fondo de Cultura Económica, México, 2010, pp. 7-74.

8 Cfr. Falk, R. y Krieger, D., The Path to zero, Taylor \& Francis, New York, 2012.

9 Cfr. EnRíQueZ, J. y Gullans, S., Evolving Ourselves. Redesigning the future of humanity one gene at a time, Penguin Group, New York, 2015, pp. 117-167. 
la transferencia de los contenidos mentales a sistemas informáticos ${ }^{10}$, o la exploración y colonización espacial ${ }^{11}$ empiezan a dejar de ser competencia exclusiva de la ciencia ficción, para ocupar la atención de científicos, historiadores, moralistas y juristas.

La conciencia de estar en una era en la que el poder humano ha alcanzado dimensiones antes desconocidas parece ser una nota común de la autopercepción de la época. Así, por ejemplo, uno de los trabajos históricos más vendidos y difundidos de los últimos años finaliza con esta declaración en la que la arrogancia, el terror y la incertidumbre parecen entremezclarse:

Hace 70.000 años, Homo Sapiens era todavía un animal insignificante que se ocupaba de sus propias cosas en un rincón de África. En los milenios siguientes se transformó en el amo absoluto de todo el planeta y en el terror del ecosistema. Hoy en día está a punto de convertirse en un dios, a punto de adquirir no solo la eterna juventud, sino las capacidades de creación y la destrucción.

[...] a pesar de las cosas asombrosas que los humanos son capaces de hacer, seguimos sin estar seguros de nuestros objetivos y parecemos tan descontentos como siempre. Hemos avanzado desde las canoas a los galeones, a los buques de vapor y las lanzaderas espaciales, pero nadie sabe dónde vamos. Somos más poderosos de lo que nunca fuimos, pero tenemos muy poca idea de qué hacer con todo ese poder. Peor todavía, los humanos parecen ser más irresponsables que nunca. Dioses hechos a sí mismos, con solo las leyes de la física para acompañarnos, no hemos de dar explicaciones a nadie. En consecuencia, causamos estragos a nuestros socios animales y al ecosistema que nos rodea, buscando poco más que nuestra propia comodidad y diversión, pero sin encontrar nunca satisfacción.

¿Hay algo más peligroso que unos dioses insatisfechos e irresponsables que no saben lo que quieren? ${ }^{12}$

10 Holmes, C., «Mind Uploading: Confronting the Privacy Challenges and Legal Ramifications of Inevitable Technological Advancements in the Context of the Fourth Amendment», en Tulane Fournal of Technology and Intellectual Property, vol. 19 (2016), pp. 191 a 206; VARY, A., «Informatics and Consciousness Transfer».

11 Cfr. Brennan, W., «Space Colonization and the Law», Harvard Fournal of Law. \& Technology. vol. 3, Spring Issue, 7 (1990) pp. 7-12; LEWIS, J.S., Mining the sky: untold riches from the asteroids, comets, and planets, Addison-Weasley Publishers, Reading Mass, 1996.

12 HaRARI, Y.N., De animales a dioses. Breve historia de la humanidad, Debate, Bogotá, 2018, pp. 455 456. 
Los desafíos de la moral y el derecho en una era en la que el hombre se percibe a sí mismo como un «dios» no se pueden subestimar. No en vano, hasta el momento, al menos buena parte de los intentos de justificación del orden moral y del sistema jurídico se basan en la aceptación de la propia limitación y vulnerabilidad. En último término, en la conciencia de no ser Dios, por lo que cabe preocuparse por las consecuencias que la negación de esta diferencia fundamental entre lo humano y lo divino puedan implicar en campo de la moralidad (¿no es acaso la autoatribución de divinidad el signo distintivo de lo demoniaco?). En todo caso, el hecho de que el signo de esta era sean el poder y la conciencia del poder plantean a las ciencias de la acción humana (derecho, moral, política) un desafío reforzado de justificación y de racionalidad.

\section{LA FILOSOFÍA DEL DERECHO Y EL ECLIPSE DE LA RAZÓN}

El primer problema que debe afrontar la Filosofía del Derecho contemporánea es lo que la teoría crítica ha llamado el eclipse de la razón ${ }^{13}$ o si se quiere la insuficiencia legitimadora del modelo de racionalidad instrumental, que es culturalmente dominante y respecto del cual la Filosofía Jurídica rara vez ha mostrado una actitud de revisión.

Para entender lo anterior se propone plantearse qué argumento fuerte podrían oponer las corrientes mayoritarias de la Filosofía del Derecho a la pretensión de abandonar el modelo democrático occidental para sustituirlo por un modelo basado en una interpretación fundamentalista de un texto sagrado. Supóngase que en dicho modelo explícitamente se subordina todo argumento racional a la expresión literal de la voluntad divina, plasmada en un texto arcaico. Supóngase, además, que dicho esquema no se adopta por imposición violenta sino por elección mayoritaria, según los cauces formales de la democracia occidental.

Dejando de lado ciertas versiones recalcitrantes del positivismo, cuya adhesión a ultranza a la teoría de las fuentes sociales obligaría a aceptar a disgusto la plena juridicidad e incluso la legitimidad -en términos sociológicos- de tal reconfiguración del sistema jurídico, hay que aceptar que un sector bastante nutrido de la teoría jurídica contemporánea rechazaría la validez de esta contradicción. El constitucionalismo moderno, que en buena medida es

13 Cfr. Horkheimer, M., Eclipse of reason, Bloomsbury, London-New York, 2004. 
uno de los escenarios prototípicos de la iusfilosofía contemporánea, parece tener bien establecido que una renuncia de tal naturaleza a la democracia es una contradicción performativa que, por ende, carece de validez (democrática) ${ }^{14}$. Sin embargo, la debilidad lógica de una argumentación de esta naturaleza es incontrovertible.

La denuncia de la contradicción performativa implícita en la renuncia consensuada al rule of law, escasamente sirve para concluir que se trata de un giro incompatible con la democracia. Pero, a quienes justamente lo que pretenden es abolir la democracia poco o nada importa el carácter democrático o antidemocrático del acto de abolición. «No se puede renunciar a la democracia o al rule of law porque es antidemocrático» es una afirmación que tiene sentido solo en la medida en que la democracia sea percibida en sí misma como un valor, y uno de mayor jerarquía que cualquier otro que se pretenda instaurar con el acto de abrogación. Ello, sin embargo, no parece evidente desde ningún punto de vista.

Una posible respuesta a la cuestión de por qué preferir la democracia sería la siguiente. Solo la democracia puede garantizar racionalidad suficiente en la elaboración de las normas y por tanto, nos preserva de la arbitrariedad ${ }^{15}$. En este punto se empiezan a evidenciar las grietas. Porque, cuando se pregunta por qué ha de valorar la racionalidad las explicaciones disponibles empiezan a flaquear. Es cierto que, por un lado, se puede suponer que el acatar un cierto tipo de pautas racionales y dialógicas opera en favor del propio interés individual o del de la mayoría. También es cierto que hasta cierto punto se puede entender que la concesión de ciertas restricciones de racionalidad, así sea meramente procedimental, es una forma de autoprotección, dada la igualdad relativa de los hombres ${ }^{16} \mathrm{y}$ la consiguiente certeza de que incluso la forma más extrema de imposición de la fuerza puede ser contrarrestada por la unión de los oprimidos. Empero, ninguna de estas razones resulta suficientemente convincente. $\mathrm{Y}$ ello, porque en el fondo, lo que se entiende como supremo es el propio interés, el deseo y el poder. La racionalidad es, a lo sumo, una

14 Cfr. Talisse, R., Democracy and Moral conflict, Cambridge University Press, Cambridge, 2005, p. 130; VAn Mill, D., Deliberation. Social Choice and Absolutist Democracy, Routledge, LondonNew York, 2006, p. 11.

15 Cfr. Habermas, J., Moral Consciousness and Communicative Action (Studies in Contemporary German Social Thought), MIT Press, 1990, pp. 202-204.

16 Cfr. Hobbes, T., Leviatán o la materia, forma y poder de una República Eclesiástica y Civil, Parte I, caps. XIII y XIV, Fondo de Cultura Económica, Buenos Aires-México D.F., 2007, pp. 100-117. 
concesión que se hace para conservar en la medida de lo posible el propio interés y el propio dominio, aunque en un escenario «ideal» de utópico egoísmo podría ser prescindible. La racionalidad deviene, pues, en un recurso, una herramienta, cuya aceptación se sustenta solamente en el miedo y el deseo. Ello es relevante toda vez que, en la medida en que, si el miedo es la única justificación para que el poder «ceda a la razón», no existen argumentos para que quien puede ejercer un poder avasallador no lo ejerza cuando puede prever razonablemente la incapacidad de los oprimidos para resistir. Por otra parte, es claro que estos argumentos no funcionan en las coordenadas de una teología en que la que Dios es poder puro, irresistible, como sucede, por ejemplo, en ciertas mitologías arcaicas o en ciertas versiones extremas del islam e incluso en algunas corrientes cristianas surgidas después de la reforma.

Alternativamente, se podría sostener que la racionalidad práctica, que parece garantizar de modo más intenso el sistema democrático, es un bien evidente en sí mismo ${ }^{17}$. Ahora bien, esta argumentación, válida desde las coordenadas de ciertas teorías de inspiración tomista, como la de la escuela anglosajona del Derecho Natural, presenta dos grandes problemas. En primer lugar, cabe la objeción de que la racionalidad práctica, en tanto que ligada a la carga existencial de la libertad y de la responsabilidad es, justamente, el objeto de uno de los más grandes temores del ser humano ${ }^{18} \mathrm{y}$, por lo tanto, del rechazo e incluso de la renuncia explícita. Esto no solamente es un punto en que parecen coincidir grandes teóricos en el terreno de la psicología, sino que también parece contar con el respaldo de la historia. Y es que, la adhesión a los movimientos totalitarios y a la promesa paternalista de librarnos del peso de nuestra propia libertad a veces parece rivalizar con el deseo emancipatorio.

La segunda objeción es que la identificación de un bien humano básico no necesariamente excluye la existencia de otros bienes ni supone su jerarquía superior respecto de estos. Por ello, frente al reclamo de sumisión total frente a la arbitrariedad divina, la identificación del carácter de bien humano básico, per se deseable, de la racionalidad práctica no es suficiente. Antes es preciso determinar cómo se resuelve el potencial conflicto entre este bien y otro que es, al menos desde las coordenadas de esta teoría, igualmente básico y evi-

17 Cfr. Finnis, J., Natural Law and Natural Rights, Oxford University Press, Oxford, 2011, pp. 8889.

18 Cfr.E. Fromm, El miedo a la libertad, Barcelona-Buenos Aires-México, 2008; SarTre, J.P., El existencialismo es un humanismo; LEVI, C., Gli Italiani e la paura della libertà, Nuova Italia/Rizzoli, Milan, 2002. 
dente: la religión. Los defensores más puristas de los postulados de la escuela anglosajona del derecho natural probablemente se apresurarán a insistir en que los bienes humanos básicos son igualmente necesarios, inconmensurables y jamás entran en conflicto entre sí de modo absoluto ${ }^{19}$. Pero en el caso de los bienes humanos básicos de la racionalidad práctica y de la religión, este conflicto solamente es evitable en la medida en que el objeto de la religión no se entienda como esencialmente contrario a la razón. Ahora bien, este postulado es incompatible con sistemas metafísicos y teológicos de carácter voluntarista, o lo que es lo mismo, solamente opera desde los postulados de la metafísica del logos supremo, presente en el pensamiento griego y cristiano (con ciertas salvedades) y ajeno a la gran mayoría de concepciones míticas y religiosas de la historia, cuyo concepto de la divinidad no implica racionalidad. Ello quiere decir, por lo tanto, que los postulados sobre la no conflictividad de los bienes humanos básicos son incomprensibles prescindiendo de cierta postura metafísica muy definida. En otras palabras, no se siguen directa y claramente de proposiciones per se evidentes que hacen innecesaria la reflexión metafísica.

Que las razones para percibir la racionalidad como un bien sean tan débiles se relaciona con la reducción del ámbito de lo racional durante la modernidad. En efecto, aunque el proyecto filosófico de la modernidad está asociado ordinariamente con la veneración cuasireligiosa de la «diosa razón», lo cierto es que en pocos periodos de la historia occidental esta ha sido tan restringida como en la modernidad. En efecto, como bien lo ha puesto de manifiesto Horkheimer la historia de la modernidad es, básicamente, la de la castración de la razón ${ }^{20}$. Según el filósofo alemán, a partir del renacimiento tardío, se abandona el paradigma de razón objetiva, subordinada a la realidad, y a su vez directiva de la verdad y criterio de corrección para sustituirlo por un modelo de razón instrumental. En las coordenadas de este nuevo paradigma, la razón aparece despojada de su referencia directa a la realidad o, al menos a la realidad más trascendente -que a causa de las disputas religiosas se tornó objeto de violenta confrontación- $\mathrm{y}$ de toda referencia objetiva metafenoménica, de modo que su ámbito se reduce al de la técnica. Razón es, pues, procedimiento. En el plano abstracto, la lógica y la matemática reemplazan a la metafísica, y en el de la acción, la planeación y la estrategia, a la ética y la política. Este nuevo y empobrecido paradigma de la racionalidad queda reducido a mero

19 Cfr. FinNis, J., Natural Law and Natural Rights, cit., p. 112.

20 Cfr. Horkheimer, M., Crítica de la Razón Instrumental, Sur, Buenos Aires, 1973 
instrumento. Es técnica, al servicio de quien quiera emplearla, para satisfacer intereses que, en sí mismos, están sustraídos a cualquier valoración objetiva. Como es evidente, esta empobrecida noción de razón no solamente es insuficiente contrapeso para el poder puro, sino que está a su servicio. La pregunta sobre por qué se ha de preferir la razón al poder, no tiene siquiera sentido. La razón no es más que un instrumento al servicio del más poderoso.

Diversos recuentos de la historia del pensamiento apuntan a que este proceso de empobrecimiento e instrumentalización de la razón está relacionado con una entendible preocupación conciliatoria, en el contexto de conflictos religiosos $^{21}$. $\mathrm{Y}$ es que, cuando la verdad religiosa se torna objeto de pugnas violentas y aparentemente irresolubles, lo «razonable» parece ser la neutralización del contenido espiritual, la supresión del discurso sobre lo absoluto. Sin embargo, existen razones para entender que este proceso de supresión del contenido espiritual está más ligado con la prevalencia y la aceptación implícita de una teología voluntarista que con el deseo de encontrar un terreno común sobre el cual reestablecer la armonía política. En efecto, aunque un voluntarismo moderado simplemente da prelación a la operación de amar sobre la de conocer, en su versión más extrema contrapone el poder y la libertad divinas a la «atadura» de la razón. La afirmación parece pía. Si Dios es verdaderamente omnipotente nada, ni siquiera la razón, ha de constreñirlo. Por esta vía Dios deja de ser el logos supremo que rige el universo, de acuerdo con la cosmovisión cristiana y ciertas vertientes de la filosofía grecorromana. Y el universo deja de ser necesariamente la obra de la racionalidad de Dios. Lo es de su poder, pero su estructura deja de estar vinculada al logos divino ${ }^{22}$.

Entender al universo como epicentro de poder, y no necesariamente de razón, no conduce necesariamente al quebrantamiento de la noción de Cosmos (pues Dios arbitrariamente podría querer dotar de una cierta racionalidad a las cosas) pero sí abona el camino para ello. En todo caso, es históricamente verificable que cuando en el siglo XIV Okham llevó a su extremo más radical el postulado voluntarista de Duns Scoto, tuvo lugar también el primer gran cuestionamiento de la objetividad del orden constitutivo de las cosas, o si se quiere, se cuestiona la realidad de las esencias que, en adelante, pasarán a ser

21 Ibid., pp. 25 y ss.

22 Cfr. BEnedicto XVI, «Fe, razón y universidad. Recuerdos y Reflexiones». Discurso pronunciado en la Universidad de Ratisbona el 12 de septiembre de 2006. Disponible on-line en http://w2.vatican.va/content/benedict-xvi/es/speeches/2006/september/documents/hf_benxvi_spe_20060912_university-regensburg.html 
consideradas por la Filosofía simples nombres o generalizaciones subjetivas. Así, no es de extrañar que la filosofía moderna pase a considerar la razón como una facultad que dota de orden subjetivo a un mundo externo cuya realidad más profunda nos es desconocida, bien sea por su radical cognoscibilidad o por su efectiva inexistencia. La conclusión que se impone es, sin embargo, siempre la misma, el hombre ordena subjetivamente los datos que le proporciona la realidad, para poder dominar el mundo. El mundo objetivo es una masa informe y el acto de razón es poder subjetivo sobre este último. La docilitas de la razón se pierde y lo que ha de imperar en adelante es algo más bien parecido a la magia ${ }^{23}$.

En este punto se debe reparar, por lo demás, en que de la concepción de la razón como facultad subjetiva para ordenar el mundo y, finalmente dominarlo, según un interés subjetivo se halla implícita una cierta forma de antropología en la que la racionalidad no ocupa el papel predominante, sino que, a imagen y semejanza de la teología, se halla subordinada al deseo y la subjetividad. Nos encontramos ante una antropología que en estricto sentido ni siquiera es voluntarista. Es una pura antropología del poder. El hombre es deseo y libertad (entendida como poder) y, solo en sentido subordinado, razón.

Es de notar que lo problemático de este modo de entender a Dios, al mundo y al hombre en función del poder no radica solamente en sus consecuencias o en su corrección o incorrección. Lo que es realmente problemático es que se trata de un supuesto implícitamente aceptado, pero rara vez discutido, ya que, una vez posicionado en la mente colectiva de Occidente (ello especialmente a partir de la Reforma protestante), no volvió a ser criticado, dada la alta identificación de la discusión de carácter religioso con el germen de la intolerancia y la violencia y el mandato de relegar la cosmovisión y la propia concepción de Dios al campo de las preferencias subjetivas.

De todo lo anterior se advierte la siguiente encrucijada. En tanto filosofía segunda, la iusfilosofía depende de las conclusiones de la metafísica y la

23 En el campo de los estudios religiosos y la antropología cultural se ha definido a la magia como el saber arcano de la manipulación o el uso -según el propio interés- de una realidad primigenia, impersonal e informe. En este sentido es el contrario directo de la religión (religación dócil a la realidad suprema). Cfr. Kaufman, Y., The Religion of Israel, trans. Moshe Greenberg, Schocken Books, New York, 1972, pp. 79-81). Esta conversion de la racionalidad en dominio y, por lo tanto, de la sabiduría en magia en la modernidad fue intuida por C.S Lewis, quien pone en boca del célebre demonio Escrutopo la promesa de un mago materialista. (Cfr. LEWIS, C.S., Screwtape Letters, Harper Collins, New York, 2000, p. 21). 
antropología. En la modernidad una y otra carecen de argumentos suficientes para aceptar la subordinación del poder y de la voluntad a la razón. Por esto mismo, la iusfilosofía parece incapaz de proporcionar una justificación de la preferencia de la racionalidad jurídica sobre el simple poder. No parece, por lo tanto, posible, encontrar una respuesta suficientemente satisfactoria a la eterna pregunta sobre la diferencia entre el derecho y la violencia, la ley y la orden del jefe de un grupo de bandido

\section{RELATIVIZACIÓN DE LA NATURALEZA}

Tanto la idea de la realidad como algo informe a la espera de ser ordenado y sometido por el hombre, como su planteamiento menos extremo, esto es, el nominalismo, tienen como consecuencia el debilitamiento radical de la noción de naturaleza. En adelante, el plano de lo natural es, a lo sumo, de lo general. Ello, por supuesto, tiene implicaciones en el concepto de derecho natural. En efecto, la generalización estadística convertida en absoluto moral parece ser el ejemplo paradigmático de paso indebido del ser al deber ser, esto es, de la falacia naturalista. Junto a esto hay que señalar que el peso del empirismo moderno llevó paulatinamente al abandono del principio de finalidad. El dogma de la irrealidad del plano metafenoménico, y de la inexistencia de las esencias, reduce la inclinación natural a los bienes básicos al instinto o la moción física, dimensión que ciertamente tiene pero con la que no se identifica y que, sobre todo, resulta claramente insuficiente para sustentar el orden práctico. En otras palabras, desde las coordenadas metafísicas y epistemológicas de la modernidad parece que existen dos opciones: o se admite la derivación de consecuencias jurídicas y morales de la simple moción instintiva y de la generalización estadística, cayendo así en el fisicalismo, o se abandona cualquier pretensión de objetividad práctica (toda vez que una auténtica exigencia moral o jurídica derivada del simple hecho de la convención es también una forma de falacia naturalista).

La idea de una estructura real, natural, metafenoménica y estable no solamente parece cuestionada por el nominalismo. Es menester reconocer que el acontecimiento más importante de la ciencia moderna, a saber, la teoría de la evolución, tiene implicaciones en la idea de especie y, hasta cierto punto, de naturaleza. En efecto, el planteamiento central de la evolución es el carácter fluido de la especie. No existe estructura fija, sino que muta de individuo en individuo y se hace predominante a través de un proceso sucesivo de adaptaciones. 
La aceptación de una realidad biológica hasta tal punto fluida, puede tener consecuencias en el orden práctico. Sin embargo, en este punto es menester aclarar que lo que aquí se sugiere no es la revisión o el rechazo de la idea de evolución en el plano biológico, cuya corrección científica parece hoy incontrovertible, sino la revisión del concepto de naturaleza. Esta revisión debe dirigirse, no tanto al concepto clásico, tal y como fue planteado entre los griegos o incluso entre los filósofos cristianos clásicos, sino al modo en que tradicionalmente se ha enseñado en la manualística y en lo que podría llamarse «escolástica de inercia». En efecto, las nociones clásicas de especie y de naturaleza no parecen per se opuestas al cambio hasta el punto de que ya autores como Agustín de Hipona y Tomás de Aquino admiten la existencia de rationes seminales, esto es, de un germen de las especies futuras en el inicio de la creación, como lo que se admite cierta dimensión de cambio y evolución.

La fluidez de las especies no es, por otra parte, problemática salvo en el caso de la humanidad. Esta cuestión no sería relevante en un contexto histórico distinto, toda vez que, en el momento actual no parece que la selección natural nos obligue a repensar la correspondencia de la especie biológica homo sapiens con la subjetividad jurídica, o la personalidad filosófica. Empero, la selección artificial a la que se ha sometido deliberadamente la especie -una auténtica obra de ingeniería, en algunos casos- y el hecho de que exista al menos la pretensión de reconfigurar el cuerpo humano según gusto y necesidad, obligan a volver a la noción de la naturaleza y a la teoría hilemórfica. El dominio sobre la dimensión somática de nuestro ser, la posibilidad de programarla con la misma técnica con la que se programa un software, el hecho de que sea objeto de la ingeniería y de la técnica, obliga a filósofos del derecho y juristas a acudir a una instancia de reflexión antropológica, a preguntarse seriamente por la relación materia-forma, alma y cuerpo en el ser humano, e incluso a plantease si el diseño somático puede, en cierto punto, romper las barreras de la especie. Asimismo, conforme avanza la tecnología informática la posibilidad de la llamada inteligencia artificial en sentido fuerte, esta parece salir del terreno exclusivo de la ciencia ficción para plantear interrogantes a filósofos y juristas. ¿La ejecución de actos racionales privados de sustento biológico independiente implica agencia moral o subjetividad jurídica autónoma?, ¿cuándo se está ante un individuo racional?, ¿existen jurídicamente hablando «cosas» racionales? Como en ningún otro momento de la historia, la iusfilosofía y la ciencia jurídica en su nivel ontológico se ven abocadas a la investigación sobre quién es el protagonista del derecho y a plantear la pregunta, hasta cierto punto inédita de si el derecho es un orden exclusivamente humano. 


\subsection{La relativización de los límites fácticos}

La reflexión sobre los problemas que el dominio técnico del hombre sobre su propia corporalidad plantea a la iusfilosofía y a la ciencia del derecho en su nivel ontológico, está relacionada, asimismo, con el problema de la desaparición o relativización de los límites y las diferencias fenoménicas. Ello no supone un cambio en la naturaleza, pero sí puede tener repercusiones en el modo de comprender lo que se deriva de ella, es decir, lo natural.

En efecto, hasta hace poco existía un claro límite entre lo físicamente posible y lo imposible. Algunas veces era tan obvio, que se tenía por evidente y su cuestionamiento era únicamente objeto de humor ${ }^{24}$. Así, por ejemplo, la distinción de los sexos era un dato biológico claro e indiscutible, y los casos en los que se presentaba cierta ambigüedad o indistinción, como el hermafroditismo, se tenían por excepcionalísimos. Y desde luego, la posibilidad de predicar la maternidad masculina, en un sentido que fuera más allá de lo metafórico, era nula. Basta con ver un noticiero actual para advertir hasta qué punto esta ya no es la realidad. Los hombres transexuales (es decir, mujeres que se sometieron a un tratamiento de readecuación para adquirir los caracteres sexuales masculinos) dan a luz y empiezan a oírse voces que reclaman la eliminación de expresiones como «mujeres embarazadas» por discriminatorias ${ }^{25}$. Pero no

24 Ello es patente, por ejemplo, en la célebre formulación de los límites de la soberanía del Parlamento Británico, recogida por DE LOLME, J. L., «Parliament can do every thing, except making a Woman a Man, or a Man a Woman», en ID., The Constitution of England; or An Account of the English Government, Book I, Chap. X. (Publicado en francés en 1771 y posteriormente en inglés. Puede consultarse en la edición de 2007, Indiana, Liberty Fund, p. 101). Esta máxima que, en su momento pareciera una obviedad e incluso como una estrategia retórica de reducción al absurdo (¿puede acaso el parlamento hacer que un hombre sea mujer o viceversa?), hoy en día parece bastante discutible y, si bien de momento, los Parlamentos no profieren órdenes semejantes, los Tribunales sí lo hacen (cfr. Corte Constitucional Colombiana, Sentencia, T-918-12. M.P. Jorge Iván Palacio Palacio; Sentencia T-771/13, M.P. María Victoria Calle Correa (Colombia); «Norsworthy v. Beard», United States District Court; Northern Disctrict of California, April 2, 2015; High Court of Justice, A, D and G v N-W Lancashire Health Authority (Reino Unido; «Sunstrom v. Frank, United States District Court for the Eastern District of Wisconsin. January 27, 2007). (Estados Unidos); JCivComConciliacionyFamiliaVillaDolores, C. J. A. y otra - solicitan autorización, LLC2007 (noviembre), 1102 (Argentina)

25 ADAMS, S. y MANNING, S., «Don't call pregnant patients 'mothers': Doctors are banned from using the word over fears it will upset those who are transgender», nota publicada en el Daily Mail (2901-2017), version en línea disponible en http://www.dailymail.co.uk/news/article-4167632/Dont-call-pregnant-patients-mothers.html; British Medical Association, A Guide To Effective Communication: Inclusive Language In The Workplace (2016), p. 5, version on line disponible en https://www. medischcontact.nl/web/file? uuid=11b96e2a-c0fb-476e-9c56-d463fbab7b3c\&owner=1e836119cfd1-4e33-a731-da3efbb2a701\&contentid=65417\&elementid=1912567. 
solo eso. Medios de comunicación de alcance mundial anuncian la posibilidad fáctica de la «maternidad masculina» gracias a un trasplante de útero ${ }^{26}$. Por otra parte, el dominio de la reproducción humana permite la desligar la concepción y el embarazo, eliminar la dualidad en el acto de la concepción (genéticamente es posible que un niño sea producto de tres donantes y se plantea la posibilidad de que solo posea la información genética de una persona, debido a la clonación). Que los casos anteriormente mencionados sean o no supuestos de cambio real de sexo o de extensión de la maternidad más allá de la feminidad es indiferente, puesto que lo que se quiere resaltar es que la barrera de posibilidad que antes parecía evidentemente infranqueable (v.gr. un hombre no puede ser madre) ha dejado de serlo.

Ello supone que algunos de los postulados que hasta el momento se tomaban como puntos de partida en la reflexión sobre el fundamento de las instituciones jurídicas, empiezan a requerir ellos mismos demostración, aunque cabría también preguntarse si la admiten.

En todo caso, la relativización del límite fáctico (el hecho de que no sea claro o evidente, no significa necesariamente que haya desparecido) obliga, por una parte, a reforzar la investigación en el nivel fenoménico, pero sobre todo a profundizar en el significado más radical de lo que se quiere decir al calificar a algo de natural. Y es que, en efecto, aunque las nociones clásicas de «natural»y «contra natura» no se refieren directamente a su realizabilidad fáctica sino a su aptitud para alcanzar bienes constitutivos de la felicidad humana, lo cierto es que hasta el momento el carácter férreo, indiscutible e inquebrantable de ciertos límites fácticos era suficiente para fundar conclusiones de derecho natural. Relativizado el límite fáctico será preciso reconducir necesariamente las discusiones a un nivel antropológico más profundo.

\section{Del univocismo a La DisOluCiÓN DEL LÍMITE}

Otra de las aporías a las que conduce la conjunción de la prohibición explícita de plantear preguntas metafísicas y la aceptación implícita de los paradigmas metafísicos de la modernidad, es la disolución de la idea de limita-

26 C. FERNÁNDEZ, «Men could get pregnant tomorrow with womb transplants» nota publicada en el Daily Mail (3-11-2017), version online en http://www.dailymail.co.uk/health/article-5048461/ Men-pregnant-tomorrow-womb-transplants.html. 
ción intrínseca. Ello aplicado al derecho, como se verá, significa nada más y nada menos que la necesidad de acudir a límites meramente externos y con frecuencia arbitrarios para separar los derechos. Es decir, el sometimiento de los derechos a la lógica conflicitivista. Asimismo, el debilitamiento de la idea de límite se asocia a una cierta propensión hacia lo utópico en el reclamo de derechos y en las pretensiones de justicia. Esta pretensión de justicia máxima o de maximización de los contenidos exigibles está peligrosamente relacionada con los extremos del totalitarismo y la ineficacia, como se verá más adelante.

Dejando de lado de momento las peligrosas consecuencias recién enunciadas, conviene examinar las razones por las cuales se afirma que el univocismo, tanto en su vertiente metafísica como en su vertiente cognoscitiva, conducen plausiblemente a la disolución del límite, toda vez que esta conexión no es evidente. Para ello se debe confrontar el univocismo moderno con un modelo de comprensión del mundo basado en la analogía y la participación.

Como es sabido, una de las ideas básicas de los sistemas clásicos de pensamiento es la aceptación de que aunque todo lo que es coincide en el ser, se diferencia justamente en qué es y en el modo en que se es. Baste recordar al respecto la fórmula aristotélica según la cual «el ser se dice de muchas maneras» ${ }^{27}$ y la anterior distinción platónica entre dos planos de realidad -sensible y eidética- en la que ya se advierten elementos de la doctrina de la participación ${ }^{28}$. Esta conciencia de la pluralidad en el modo y la intensidad de ser llega a su más alta expresión al ser incorporada a la doctrina cristiana sobre el cristianismo y más concretamente en el corpus metafísico de Tomás de Aquino. La doctrina tomista del Ser partiendo de la consideración de la limitación y contingencia de todos los entes, llega a la conclusión de que su baja intensidad en el ser, insuficiente para dar razón de su propia existencia, remite a otro nivel de Ser, en el que el acto de ser se identifica con la esencia y se predica con necesi$\mathrm{dad}^{29}$. Este plano del Ser (que en Santo Tomás se identifica con el de un Dios personal) contiene en sí de modo pleno todas las perfecciones y sustenta la existencia y las perfecciones de todos los demás seres contingentes. En otras palabras, todo lo que existe -y conocemos por experiencia directa- es porque

27 Cfr. Aristóteles, Metafísica, III, 1003 a 34 y su eco en la filosofía tomista patente en textos como De Principis Naturae, cap. 6.

28 Cfr. LA Touche, F., «Plato's doctrine of participation», Hermathema, ${ }^{\circ} 59$ (May, 1942), pp. 6-19; PATTESON, R., «Plato's theory of participation: platonic forms and the making sense objects», The Society for Ancient Greek Philosophy Newslette, 23 (1980).

29 Cfr. Tomás DE Aquino, Ente et Essentia, Cap. VI; Summa Theologiae, I. q. 2, a.3 
participa del ser y se mantiene en él ${ }^{30}$. Y la esencia se define al final por el grado de participación ${ }^{31}$, lo cual remite necesariamente a la idea de límite. Hablar de esencia es, en efecto, referirse tanto a un grado de participación en el ser como al hecho de que se participa hasta cierto punto y con cierta intensidad. La definición esencial, en efecto, tiene tanto de afirmación como de privación. En el plano entitativo se es en la misma medida en que se deja de ser otra cosa.

Ahora bien, de esta concepción, aparentemente alejada de la realidad práctica, se siguen importantes consecuencias en el campo antropológico y moral. En efecto, la personalidad humana y los atributos que de ella se predican se entienden, en definitiva, en función del alto grado de participación que posee el hombre. ${ }^{32}$ De esta visión, se sigue también que todas las perfecciones que se predican del hombre y de las demás cosas existentes, no se dicen en sentido absoluto sino en el contexto de la participación y, por tanto, de modo limitado. Así pues, la libertad, el dominio, el conocimiento, la bondad o la justicia humanas se entienden, por definición, imperfectas y limitadas ${ }^{33}$.

Ello se traduce en una cierta moderación en las pretensiones, los reclamos y las exigencias prácticas. La libertad y el dominio se entienden siempre en un sentido relativo, como órbitas limitadas por la misma estructura no absoluta del hombre, cuyo ser no es pleno o absoluto. Se es libre a partir de lo dado y lo dado tiene una estructura que no está sujeta, ella misma, a la libertad. Se domina lo externo, pero bajo el entendido de que el dominio del que es capaz el ser limitado no puede ser ilimitado o absoluto. Esta simple realidad, que en apariencia resulta muy abstracta, tiene repercusiones reales en la concepción de la naturaleza del derecho real de dominio, indiscutidamente limitado y e impregnado de una dimensión de custodia en la mentalidad cristiana

30 Cfr. Tomás De Aquino, Summa Theologiae, I, q. 44, a.1.

31 Cfr. Forment, E., Ser y persona, Barcelona, Publications i Universitat de Barcelona, 1983, p. 60; RizHA, J., Perfecting Human Actions: St. Thomas Aquinas on human participation on Eternal Law, The Catholic University of America Press, Washington D.C., 2009, p. 12.

32 Cfr. Hervada, J., Lecciones Propedéuticas de Filosofía del Derecho; Mora Calvo, H.R., «El hombre en Santo Tomás de Aquino», Revista de filosofía de la Universidad de Costa Rica, XXXIII, $\mathrm{n}^{\circ} 80$ (1995), pp. 87-94

33 Cfr. HerVADA, J., «El valor del Derecho: la justicia» texto inédito contenido en «Objeto, fuentes y método del Derecho canónico», expediente de oposiciones a la Cátedra de Derecho Canónico de la Facultad de Derecho de las universidades de Granada, Murcia y Zaragoza. Años 1963-1964. En Archivo General de la Administración, Alcalá de Henares, Ubicación: IDD (05)001.010, Top. 32/53 (signaturas provisionales, legajos en reinstalación) 
pre-moderna y limitado de modo eminentemente accidental y extrínseco en la concepción de propiedad imperante en la cultura moderna.

De esta comprensión se siguen asimismo importantes consecuencias en lo que tiene que ver con las expectativas que se tienen respecto de las posibilidades de la justicia humana. En efecto, si la justicia se predica en el hombre de modo analógico y siempre absoluto, resulta conceptualmente imposible exigir o esperar la justicia humana absoluta y, toda vez que, en el plano humano es imposible esta realización plena de la justicia se sigue como consecuencia que connatural a la aspiración de lo justo es la aceptación de un cierto marco de tolerancia a la injusticia. O si se quiere enunciar lo mismo en otras palabras, dado que la justicia perfecta es imposible, y solo es posible la justicia limitada e imperfecta, la reclamación de justicia absoluta deviene, en sí misma, en una forma de injusticia ${ }^{34}$.

Hacia el siglo XIV la teoría de la participación y la concepción analógica del ser empiezan a ceder del ser y el predicar caracterizada por la univocidad y la equivocidad. El giro empieza a ser perceptible en la obra de Duns Scoto, quien niega el intermedio entre la identidad y la diferencia de los conceptos, o si se quiere, entre la univocidad y la equivocidad..$^{35}$ La metafísica, todavía preservada del decreto de muerte que le avendrá más tarde, empieza a entenderse como el estudio del ser común, y las diferencias cualitativas entre lo que es plenamente y lo que es por participación pasan a ser diferencias cuantitativas entre lo infinito y lo finito ${ }^{36}$. Las diferencias formales empiezan, pues, a reducirse a diferencias en el quantum. El abandono de la participación y la analogía se refuerza más adelante en la obra de Guillermo de Ockham, para quien las diferencias en el quantum, pasarán a ser diferencias en la generalización y por último, en la denominación del universal.

Lo anterior no es irrelevante en las cuestiones prácticas. Si se pierde de vista la diferencia entre los planos del ser pleno y el ser participado (cuya esencia se define en términos de grado o limitación en la participación), el ser se predica del mismo modo respecto de Dios y las criaturas, distinguiéndose solo cuantitativamente. Dios tiene más ser, pero no es más perfectamente. Dios es más justo, más libre, domina más intensamente, pero la justicia, la libertad

34 Cfr. Hervada, J., «El valor del derecho: la justicia», cit.

35 Cfr. Nafarrete Susaeta, A., «Los fundamentos de la unicidad del ser y la cognoscibilidad de Dios en Juan Duns Escoto», Anuario de Historia de la Iglesia, vol. X (2001), p. 494.

36 Ibidem. 
y el dominio divinos no difieren esencialmente de la justicia, la libertad y el dominio humanos. Ello, por supuesto, relativiza la moderación de las pretensiones humanas respecto de las dimensiones antedichas de justicia, libertad y dominio, pues, en principio, las diferencias de más o menos se mitigan con la agregación o la sustracción.

Ahora bien, con el correr de los siglos, la secularización romperá definitivamente la barrera ya debilitada entre los planos del ser y la predicación divinos y los planos de ser y la predicación a nivel creatural. Si en su momento Scoto y Ockham aceptaron la distinción cuantitativa infranqueable entre lo finito y lo infinito, esta última barrera se pierde en los modelos deístas ilustrados, que abren la puerta a la declaración de la irrelevancia de Dios y conciben al mundo de un modo totalmente autónomo. En este modelo solo existe un plano de predicación del ser, y las diferencias entre los entes pasan a estar definidas únicamente de modo lingüístico y hasta cierto punto arbitrario. Rota la barrera de lo finito y lo infinito, todo es potencialmente infinito. La justicia, la libertad y el dominio, son susceptibles de un aumento siempre progresivo. La esencia, reducida primero a quantum y luego a nombre no sirve de límite interno.

Que conceptualmente no sea imposible pensar en órbitas de dominio omniextensivas, o de una justicia ilimitada tiene consecuencias históricas bastante relevantes. Respecto de lo segundo, baste pensar que es justamente esta pretensión de justicia, rectitud y moralidad infinita lo que se encuentra en la base de no pocos totalitarismos ${ }^{37}$. En lo que tiene que ver con el carácter no esencialmente limitado de las órbitas de poder (libertades, facultades, dominio), las consecuencias son igualmente perturbadoras, porque es axiomático que allí donde hay dos o más seres dotados de libertades y órbitas de dominio en principio ilimitadas, estos eventualmente entrarán en conflicto, así este permanezca latente. La violencia actual, o la simple, pero siempre presente, amenaza de violencia termina constituyéndose en único criterio de limitación de los poderes (jurídicos) del individuo.

37 Esta afirmación no ha de entenderse como sinónimo de la vinculación de sistemas éticos no relativistas, esto es, que aceptan la existencia de contenidos materiales absolutos, y los sistemas totalitarios ni en el sentido de la asociación más amplia entre verdad y certeza, por una parte, y violencia por la otra (cfr. Menand, L., Metaphysical Club, p. 61). Simplemente se trata de la constatación de que en el corazón de los totalitarismos modernos, especialmente en los de corte marxista, se encuentran pretensiones más bien mesiánicas, promesas de llegar al «fin de la opresión», restablecer totalmente la justicia y acabar para siempre con el desorden. El peligro no radica en que estos sistemas afirmen la existencia de verdades absolutas, sino que se arroguen la capacidad de poseerla de modo pleno, sin posibilidad de error, ni limitaciones en su intensidad. 


\section{UNIVOCIDAD O EQUIVOCIDAD DEL DERECHO Y MONISMO EN LA PREDICACIÓN DEL DOMINIO}

El debilitamiento de la analogía del ser apareja una consecuencia significativa en los planos lógico y lingüístico: el debilitamiento consecuencial del pensamiento y la predicación analógicos. Negada la analogía del ser, la analogía de los conceptos o de la palabra se pierde del horizonte y solo hay lugar para significaciones unívocas o equívocas.

Lo anterior tiene relevancia toda vez que, como bien es sabido, el derecho es uno de los conceptos que la tradición clásica definió analógicamente ${ }^{38}$. Así pues, el cambio del paradigma lógico y lingüístico, que excluye la analogía tiene un impacto necesario en el modo de entender lo jurídico. La consecuencia más directa es la dificultad para conciliar las dimensiones normativas y subjetivas de lo jurídico, patentes incluso, a partir de una precomprensión del derecho. Las teorías jurídicas de la modernidad se caracterizan en consecuencia, o bien por subsumir una de estas dimensiones del derecho en la otra, como ocurre por ejemplo en el caso de la caracterización kelseniana del derecho subjetivo $^{39}$, o bien por plantear un perenne conflicto entre norma y libertad que termina resolviéndose en términos de limitación externa y coacción directa o implícita. De ahí que entre los modernos, y solo entre los modernos, tenga sentido la apelación a figuras como la del abuso del derecho, concebido como oposición real entre las órbitas objetiva y subjetiva del derecho ${ }^{40}$.

Sobre las consecuencias de esta visión normativo/subjetivista que se debate entre la equivocidad y el univocismo existe una creciente conciencia. Parece

38 Cfr. ARISTóteles, Ética Nicomaquea, Libro V, 1129a 25 y ss; TOMÁs DE AQUINO, Suma de Teología, I-II, q. 57, art. 1, ad.1.

39 Sobre este asunto cfr. ÁlvareZ GálvEZ, I., «Sobre el concepto de derecho subjetivo de Hans Kelsen», Boletín de la Facultad de Derecho de la UNED, no 17 (2001), pp. 21 a 72, disponible en línea en la página http://e-spacio.uned.es/fez/eserv/bibliuned:BFD-2001-17-C830506E/PDF [consulta: 19-02-2018].

$40 \mathrm{Al}$ respecto resultan especialmente ilustrativas las siguientes consideraciones de Josserand sobre el abuso del Derecho: «(u)n acto sí puede ser a la vez conforme y contrario al derecho, porque la palabra envuelve dos acepciones muy diferentes. Ora designa el conjunto de la ciencia jurídica, de la juridicidad, el derecho objetivo, ora contempla tal o cual prerrogativa determinada, los derechos subjetivos, como el derecho de propiedad o de acudir a la justicia, y esta simple distinción basta para dar la clave del problema. El acto abusivo es el que, cumplido en virtud de un derecho determinado, de un derecho subjetivo como el de la propiedad, es sin embargo, contrario al derecho considerado en conjunto» (JOSSERAND, L., «La relatividad y el abuso de los derechos», en ID., Del abuso del Derecho y otros ensayos, Temis, Bogotá, 1982, p. 25). 
conveniente, sin embargo, resaltar que esta característica se predica también de cada uno de los significados del derecho. En otras palabras, junto con una concepción global del derecho marcada por la tensión entre el disyuntivismo y el univocismo, existe una tendencia al desconocimiento de la complejidad y analogía en las teorías de la norma y del derecho subjetivo. La vertiente univocista parece destacar. En lo que tiene que ver con la norma, resalta el «monismo legalista» que hizo furor en la era de la codificación, tanto en lo que tiene que ver con la definición misma de la norma como en lo que se refiere al arduo problema de su interpretación. Dicho modo de ver el elemento normativo ciertamente se ha morigerado en la teoría jurídica de la segunda mitad del siglo $\mathrm{XX}$ y en el presente siglo, que por regla general han mostrado apertura al reconocimiento de diversos modos de predicación normativa (regla, principio o valor) y han estructurado diversas teorías sobre la articulación de unos y otros en un sistema complejo (especialmente el constitucional) ${ }^{41}$. No ocurre lo mismo en el plano de la teoría de los derechos subjetivos que, por regla general, tienden a entenderse según el modelo de un único modo de dominio que se toma como prototipo del derecho subjetivo: el que se ejerce sobre la mercancía. Las primeras observaciones formuladas en este sentido provienen de las apreciaciones sobre la mercantilización progresiva de bienes como la tierra, el dinero, la fuerza de trabajo e incluso la misma persona del trabajador. El modelo de todo derecho pasa a ser el dominio ${ }^{42}$ y no cualquier dominio sino el que se ejerce sobre el bien mueble, con sus notas de disposición irrestricta y transferibilidad. El mercado es el escenario social por excelencia ${ }^{43}$. No se niega, por supuesto, que la misma dinámica social haya obligado a imponer límites externos a este dominio. Así, por ejemplo, el conflicto agrario, los movimientos obreros, las problemáticas ambientales, o los evidentes abusos de la posición dominante, han llevado a la moderación sustancial de esta idea en ciertos ámbitos. Se insiste, nuevamente, que esta limitación histórica es una limitación externa, surgida del conflicto, de la necesidad de conciliación para evitar la violencia.

En todo caso, al tratarse de una limitación externa, cabe decir que esta se refiere al extremo que se torna problemático, pero no cambia en absoluto

\footnotetext{
41 A modo de ejemplo, podría citarse la articulación que de estos elementos hace ALEXY, R., Teoría de los Derechos Fundamentales, Centro de Estudios Constitucionales, Madrid, 1993, pp. 71-170.

42 Cianciardo, J., El ejercicio regular de los derechos, AdHoc, Buenos Aires, 2007, p. 163.

43 Ibidem.
} 
la asunción de base sobre el paradigma del derecho subjetivo, configurado sobre la noción de dominio, disponibilidad y transferencia. Por ello la morigeración no ha evitado la expansión de los procesos de mercantilización sobre una órbita cada vez más amplia de derechos. Así, por ejemplo, en el ámbito de la protección de la propiedad intelectual y el derecho de patentes, se ha desarrollado un modo de entender las ideas, los universales, las especies mismas, como objetos de dominio, o si se quiere, se ha llegado a un punto de «mercatilización de las ideas» (commodification of ideas) ${ }^{44}$, de las esencias y las especies. ${ }^{45}$ El extremo más claro, es, sin embargo, la conceptualización de la vida misma y las diversas esferas de la integridad física como formas de propiedad, y por ende, de disposición. Esta visión se halla, para algunos, presente en los mismos momentos fundacionales del constitucionalismo moderno. Así, por ejemplo, aunque textualmente ausente en los escritos políticos de Locke, no faltan quienes insisten en ver en ellos una conceptualización de la vida como una especie de propiedad ${ }^{46}$ y el dominio de las cosas externas una extensión del autodominio (libertad). Sea como fuere, parece innegable que la ampliación de la órbita de los objetos que se entienden dominables y la asunción de un solo modo de dominio, que tiene su nota determinante en la transfereribilidad y la disposición, tiene al menos una correlación temporal con el surgimiento de un modo de comprender a la vida y al cuerpo como objetos de un derecho de dominio, asimilable al que se ejerce sobre las cosas. Con especial elocuencia, esta conexión fue planteada por el jurista norteamericano Axel Tiesen en un brevísimo artículo, en principio referido a la cuestión indemnizatoria. En él se plantea de modo explícito que la ampliación de la órbita del derecho a la propiedad experimentada hasta el momento debería redundar en la posibilidad de entender a

44 Cfr. Bowrey, K., «Law, aesthetics and copyright historiography: a critical reading of the genealogies of Martha Woodmansee and Mark Rose», en I. Alexander y H.T. Gómez Arostegui, Research Handbook on the History of Copyright Law, Edward Elgar Publishers, Cheltenham-Northhampton, p. 51

45 Lohmann, L., «Performative Equations and Neoliberal Commodification: The Case of Climate», en Bram Büscher et al. (ed.), Nature Inc.: Environmental Conservation in the Neoliberal Age, University of Arizona Press, Tucson, 2014, p. 158; BraHA, O., «The Commodification of Patents 1600-1836: How Patents Became Rights and Why We Should Care», 38 Loy. L.A. L. Rev. 177 (2004).

46 Cfr. Seagrave, S. A., The Foundations of Natura Morality. On the Compatibility of Natural Rights and the Natural Law, University of Chicago Press, Chicago, 2014, pp. 75-76. Una lectura más pausada de Locke sugiere, sin embargo, que la vida es fundamento y no especie de la propiedad sobre las cosas. 
la vida misma como objeto de propiedad, al menos en cierta medida. ${ }^{47}$ Dicha ampliación parece dada por sentado en la teoría constitucional moderna. En efecto, el planteamiento contemporáneo de los problemas relativos al derecho a la vida, ha sido planteada elocuentemente por un eminente iusfilósofo como la cuestión relativa al dominio de la vida ${ }^{48}$, nombre que responde ciertamente a la clase de litigios que conciernen al tema: propiedad de embriones humanos $^{49}$, o la libre terminación de la vida propia ${ }^{50}$ o ajena ${ }^{51}$. Ello sin contar las múltiples problemáticas relativas a la autoconfiguración de la corporalidad, bien sea en su versión de reconfiguración sexual (en algunos casos enfocada desde la perspectiva del derecho a la salud ${ }^{52}$ pero en otros como expresión de la autonomía $)^{53}$ o en la más radical problemática relativa a la alienabilidad incluso comercial del propio cuerpo ${ }^{54}$ o derecho diseño corporal extremo (v.gr.

47 Cfr. Tiesen, A., «Should Human Life be Considered as Property?», Central Law fournal, vol. 79 (1914), pp. 57 a 59.

48 Cfr. Dworkin, R., Life's Dominion: an argument about abortion, euthanasia, and individual freedom, Alfred. A. Knopf, New York, 1993.

49 Cfr. Kass v. Kass, 235 A.D.2d 150 (N.Y. App. Div. 1997); A.Z. v. B.Z., 725 N.E.2d 1051 (Mass. 2000).

50 Washington v. Glucksberg, 521 U.S. 702 (1997); Colombia Corte Constitucional, Sentencia C-355/2006. M.P.; Litowitz v. Litowitz, 146 Wash. 2d 514, 48 P.3d 261 (2002).

51 Roe v. Wade, 410 U.S. 113 (1973); Planned Parenthood v. Casey, 505 U.S. 833 (1992).

52 Fajardo Arturo, L.A., «Derechos humanos y LGTB. Marco legal en Colombia», en J.F. Serrano Amaya (ed.), Otros cuerpos, otras sexualidades, Pontificia Universidad Javeriana-Instituto Pensar, Bogotá, 2006, p. 149.

53 Expresión clara de esta perspectiva, es lo que reza textualmente el llamado Bill of Transgender Rights propuesto por la International Conference on Transgender Law and Employment Policy (1994): «All human beings have the right to control their bodies, which includes the right to change their bodies cosmetically, chemically, or surgically, so as to express a self-defined gender identity. Therefore, individuals shall not be denied the right to change their bodies as a means of expressing a self-defined gender identity; and further, individuals shall not be denied Human or Civil Rights on the basis that they have changed their bodies cosmetically, chemically, or surgically, or desire to do so as a means of expressing a self-defined gender identity» Cfr. asimismo, LOZANO VILLEGAS, G., «Libre desarrollo de la personalidad y cambio de sexo: el transexualismo», en IV Fornadas de Derecho Constitucional y Administrativo, Universidad Externado de Colombia, Bogotá, 2003, pp. 217 a 240.

54 Sobre las problemáticas surgidas en torno a la posibilidad de tratar al cuerpo humano dentro de los esquemas conceptuales del derecho de propiedad cfr. DE LORENZO, F., «El cuerpo humano que se vuelve cosa, cosas que se vuelven cuerpo humano», La Ley, Buenos Aires, 2010-B-807; RABBI-BALDI, R., «La experimentación en seres humano. Reflexiones a partir del nuevo Código Civil y Comercial de la Argentina», en ID. (coord.), Los derechos de la persona en el nuevo Código Civil y Comercial. Aproximación a algunos aspectos novedosos, Universidad de Buenos Aires, Thomson Reuters-La Ley, Buenos Aires, 2017, pp. 95-118; y RABBI-BALDI, R. y LAISE, L., «Una mirada filosófica a la centralidad de la persona en el Nuevo Código Civil y Comercial de la Nación Argentina», en RABBI-BALDI, R. (coord.), Los derechos de la persona..., cit., p. 10. 
fenómeno cyborg $)^{55}$. A nivel fáctico y especialmente económico, la «mercantilización del cuerpo», parece ser un hecho. A nivel jurídico las restricciones parecen relativizarse, imposible pasa a ser posible o al menos, discutible ${ }^{56}$.

La nueva lógica implícita en la reducción de todo a dominio que incluye la total disposición, esto es, a la modalidad propia del imperio sobre la mercancía, esto es, el pensamiento monista que define a todo derecho como propiedad y que admite un solo modo de dominio, diluye las fronteras conceptuales y jurídicas entre sujeto y objeto de derecho o, si se quiere, entre lo disponible y lo indisponible. La fórmula de la libertad, desde el prisma de este pensar monista y reduccionista, en tanto que contentiva de una órbita de total disposición incluso sobre el propio ser, paradójicamente es la misma fórmula jurídica de la esclavitud (propiedad sobre un ser humano).

Que el monismo en la concepción del derecho y los modos de dominio al hacer de la mercancía el modelo de bien jurídico pueda llegar a diluir las fronteras entre sujeto y objeto de derecho tiene profundas consecuencias en lo que respecta a la afirmación de la dignidad como fundamento del derecho. En efecto, el reconocimiento de la dignidad como fundamento del orden jurídico depende de la aceptación de una peculiar eminencia ontológica y de una dimensión exigitiva consiguiente, que excluye cualquier forma de $\operatorname{cosificación~}^{57}$.

55 A este respecto resulta diciente lo afirmado por el Prof. G. Ramachadran respecto de la inconveniencia de predicar la inalienabilidad y el carácter absoluto del derecho a la integridad corporal: «I argue that as a normative matter, we should not use dignity or autonomy arguments to promote any monolithic right to bodily integrity, whether alienable or not. However, my critique of a monolithic concept of a right to bodily integrity, demarcated by the organic, human, physically integrated body's borders, still leaves room to justify a more nuanced version of rights in the body. Thus, I consider dignity and autonomy as approaches to justifying more nuanced rights in the human body, ones whose legal borders may not line up with the human body's physical borders. I conclude that dignity as a basis for singling out the body and prohibiting these sales is too arbitrary for a pluralistic society. Autonomy as a basis for prohibiting the regulation of these sales ignores the inevitable presence of economic and cultural coercion. Finally, I consider and critique the capability approach to justifying nuanced rights in the human body, since it arguably solves many of the problems identified with dignity and autonomy» (RAMACHANDRAN, G., «Against the Right to Bodily Integrity: Of Cyborgs and Human Rights», Denver University Law Review, 87 [2009], pp. 3-4); Cfr. también, Hables Gray, C., Cyborg Citizen. Politics in the Post-buman age, New York-London, pp. 26 y 27.

56 Cfr. Cherry, M., «Embracing the commodification of human organs: Transplantation and the freedom to sell body parts», Saint Louis University Fournal of Law \& Policy, 2 (2009), pp. 359378; Marshall, P.A.; ThOMAS, D.C. y DaAR, A.S., «Marketing human organs. The autonomy paradox», Theoretical Medicine and Bioethics, 17 (1996), pp. 1-17.

57 Cfr. Hervada, J., Lecciones Propedéuticas de Filosofía del Derecho, Pamplona, Eunsa, 2000, pp. 448449; «Los derechos inherentes a la dignidad de la persona humana», Humana Iura, 1 (1991), 
Dignidad implica, pues, una distinción radical entre personas y cosas, lo que está y no está en el mercado, lo que pertenece al reino de los fines y lo que es simplemente medio ${ }^{58}$. No extraña, por tanto, que en el seno de las discusiones biojurídicas, donde el problema de mercantilización de todo derecho se expresa en las polémicas sobre la disponibilidad del propio ser, se plantee la reformulación de la dignidad, en términos de empoderamiento (dignity as empowerment), y se reconozca explícitamente su posible colisión con la más tradicional concepción de la dignidad como límite (dignity as constraint) ${ }^{59}$.

De lo anterior se sigue que la reducción de todo bien a mercancía y la tendencia a la conceptualización de todo derecho subjetivo según el modelo del derecho de propiedad no tiene una relevancia exclusivamente teórica. Por el contrario, propicia la reducción de todo razonamiento jurídico a la lógica del negocio y la transferencia. Lógica que, por lo demás, en el mundo moderno no obedece a otro modelo que el de la utilidad y el interés. Los conflictos jurídicos quedan reducidos, pues, a conflictos de interés, que finalmente se resuelven según los mecanismos del mercado, es decir, mediante el poder de la fuerza económica. La razón no es en estricto sentido límite al poder, sino simple instrumento de negociación, puesto al servicio del interés y los poderes. Nuevamente, una cuestión pre-jurídica, en este caso la tendencia al univocismo lógico, genera dificultades para justificar que la fuerza ceda a la razón.

\section{EN LUGAR DE CONCLUSIONES... UNA PREGUNTA ABIERTA}

De lo dicho hasta el momento se colige que las bases metafísicas, lógicas $\mathrm{y}$ antropológicas predominantes $\mathrm{o}$, al menos indiscutidas, en la modernidad plantean serios obstáculos a la justificación del derecho o, lo que es lo mismo, a la pretensión de racionalidad (más que instrumental) de lo jurídico y, por lo

pp. 345-379. A nivel judicial, cfr. C. Pardo Schlesinger, Salvamento Parcial y aclaración de voto a la sentencia T-423 de 2017 de la Corte Constitucional (Colombia) y CSJN, «Bahamondez, Marcelo s/ medida cautelar», Fallos 316:479 (1993), consid. 12 del voto concurrente con la mayoría de los jueces Barra y Fayt, luego reiterado, entre otros, en Fallos 323:3229 y 327:3753 (Argentina).

58 KanT, I., Fundamentación de la Metafísica de las Costumbres (ed. bilingüe), Ariel, Barcelona, 1999 (\$435), pp. 199-201.

59 Cfr. BeYleveld, D. y Brownsword, R., Human Dignity in Bioethics and Biolaw, Oxford University Press, Oxford, 2001, pp. 9-27. 
tanto, de la existencia de auténticas razones para renunciar al imperio, abierto o soterrado, de la fuerza y el interés.

De ahí se sigue, por consiguiente, que la justificación del derecho (aspecto quintaesencial de la Filosofía Jurídica) ni se puede dar por sentada o declarar irrelevante, ni se puede realizar sin una remisión previa a problemas y reflexiones que, por ser fundamentales, se encuentran más allá de los límites epistemológicos que definen lo propiamente iusfilosófico. En otras palabras, si se ha de justificar el orden jurídico, primero se ha de justificar el orden, si se quiere defender una racionalidad más que instrumental se habrá de indagar primero sobre una estructura racional objetiva y un principio racional que la sustente, si se han de combatir las pretensiones absolutistas del orden humano, se ha de reflexionar primero sobre la contingencia de las cosas y su remisión a otro plano del ser, este sí necesario. Ninguna de estas cuestiones es, sin embargo, propia de la Filosofía del Derecho. Siendo esto así, cabe preguntarse si es posible o vale la pena hacer una iusfilosofía condenada a eternas aporías o a la incapacidad justificatoria. ¿Debe, acaso, el iusfilósofo convertirse en metafísico?

\section{BiBLIOGRAFÍA}

\section{Libros y artículos}

ADAMs, S. y MANNING, S., «Don't call pregnant patients 'mothers': Doctors are banned from using the word over fears it will upset those who are transgender», nota publicada en el Daily Mail (29-02-2017), http://www.dailymail.co.uk/ news/article-4167632/Don-t-call-pregnant-patients-mothers.html;

Alexy, R., Teoría de los Derechos Fundamentales, Centro de Estudios Constitucionales, Madrid, 1993.

Álvarez GálvEZ, I., «Sobre el concepto de derecho subjetivo de Hans Kelsen», Boletín de la Facultad de Derecho de la UNED, n 17 (2001), pp. 21-72, http://espacio.uned.es/fez/eserv/bibliuned:BFD-2001-17-C830506E/PDF [consulta: 19-02-2018].

ARISTÓTELES, Metafísica (edición trilingüe por Valentín García Yebra), Gredos, Madrid, 1987.

Bauman, Z., La globalización. Consecuencias humanas, Fondo de Cultura Económica, México, 2010.

BENEDICTO XVI, «Fe, razón y universidad. Recuerdos y Reflexiones». Discurso pronunciado en la Universidad de Ratisbona el 12 de septiembre de 2006. http:// w2.vatican.va/content/benedict-xvi/es/speeches/2006/september/documents/ hf_ben-xvi_spe_20060912_university-regensburg.html 
Beyleveld, D. y Brownsword, R., Human Dignity in Bioethics and Biolaw, Oxford University Press, Oxford, 2001.

BOWREY, K., «Law, aesthetics and copyright historiography: a critical reading of the genealogies of Martha Woodmansee and Mark Rose» en I. Alexander y H.T Gómez Arostegui, Research Handbook on the History of Copyright Law, Edward Elgar Publishers, Cheltenham-Northhampton, 2016.

BraHA, O., «The Commodification of Patents 1600-1836: How Patents Became Rights and Why We Should Care», 38 Loy. L.A. L. Rev. 177 (2004).

BRENNAN, W., «Space Colonization and the Law», Harvard Fournal of Law. \& Technology, vol. 3, Spring Issue, 7 (1990), pp. 7-12.

British Medical Association, «A Guide To Effective Communication: Inclusive Language In The Workplace» (2016), p. 5, https://www.medischcontact.nl/web/ file? uuid=11b96e2a-c0fb-476e-9c56-d463fbab7b3c\&owner=1e836119-cfd14e33-a731-da3 efbb2a701\&contentid=65417\&elementid $=1912567$.

Cianciardo, J., El ejercicio regular de los derechos, AdHoc, Buenos Aires, 2000.

Cherry, M., «Embracing the commodification of human organs: Transplantation and the freedom to sell body parts», Saint Louis University Fournal of Law \& Policy, 2 (2009).

DAAR, A.S., «Marketing human organs. The autonomy paradox», Theoretical Medicine and Bioethics, 17 (1996), 1-17.

De Lolme, J. L., The Constitution of England; or An Account of the English Government, Liberty Fund, Indiana, 2007.

DE LorEnZO, F., «El cuerpo humano que se vuelve cosa, cosas que se vuelven cuerpo humano», La Ley (2010-B-807).

DwORKIN, R., Life's Dominion: an argument about abortion, euthanasia, and individual freedom, Alfred. A. Knopf, New York, 1993.

ENRÍQUEZ, J. y GulLANS, S., Evolving Ourselves. Redesigning the future of humanity one gene at a time, Penguin Group, New York, 2015.

FAjARdo ArTuro, L.A., «Derechos humanos y LGTB. Marco legal en Colombia», en J.F. Serrano Amaya (ed.), Otros cuerpos, otras sexualidades, Pontificia Universidad Javeriana-Instituto Pensar, Bogotá, 2006.

Falk, R. y Krieger, D., The Path to zero, Taylor \& Francis, New York, 2012.

FERNÁNDEZ, C., «Men could get pregnant tomorrow with womb transplants», nota publicada en el Daily Mail, 03-12-2017, http://www.dailymail.co.uk/health/article-5048461/Men-pregnant-tomorrow-womb-transplants.html

FINNIS, J., Natural Law and Natural Rights, Oxford University Press, Oxford, 2011

Forment, E., Ser y persona, Publications i Universitat de Barcelona, Barcelona, 1983

Fromm, E., El miedo a la libertad, Barcelona-Buenos Aires-México, 2008

GraY, C.H., Cyborg Citizen. Politics in the Post-human age, New York-London, 2001.

Grocio, H., De iure belli ac pacis, De iure belli ac pacis libri tres: in quibus ius naturae \& Gentium: item iuris publici praecipua explicantur, Olms, Hildesheim, 2006.

Harari, Y.N., De animales a dioses. Breve historia de la humanidad, Debate, Bogotá, 2018. 
Harvey, D., The Condition of Postmodernity: An Enquiry into the Origins of Cultural Change, Blackwell, Cambridge, MA, 1990.

Habermas, J., Moral Consciousness and Communicative Action (Studies in Contemporary German Social Thought), MIT Press, 1990.

Herrera Jaramillo, F.J., Filosofía del Derecho, Ediciones Universidad Javeriana, Bogotá, 1996.

HervadA, J., «Lo nuevo y lo viejo en la hipótesis etiamsi daremus de Grocio», Revista de Estudios Histórico-Zurídicos, VII (1982).

- Lecciones Propedéuticas de Filosofía del Derecho, Pamplona, 2000.

- ¿Qué es el Derecho? La moderna respuesta del realismo jurídico, Eunsa, Pamplona, 2002.

- «El valor del Derecho: la justicia» texto inédito contenido en «Objeto, fuentes y método del Derecho canónico». Expediente de oposiciones a la Cátedra de Derecho Canónico de la Facultad de Derecho de las universidades de Granada, Murcia y Zaragoza. Años 1963-1964. En Archivo General de la Administración, Alcalá de Henares, Ubicación: IDD (05)001.010, Top. 32/53 (signaturas provisionales, legajos en reinstalación).

HobBes, T., Leviatán o la materia, forma y poder de una República Eclesiástica y Civil, Fondo de Cultura Económica, Buenos Aires-México D.F., 2007.

Holmes, C., «Mind Uploading: Confronting the Privacy Challenges and Legal Ramifications of Inevitable Technological Advancements in the Context of the Fourth Amendment», Tulane Fournal of Technology and Intellectual Property, vol. 19 (2016), pp. 191-206.

HorkHeimer, M., Eclipse of reason, Bloomsbury, London-New York, 2004.

- Crítica de la Razón Instrumental, Sur, Buenos Aires, 1973.

International Conference on Transgender Law and Employment Policy, Bill of Transgender Rights (1994).

JOSSERAND, L., «La relatividad y el abuso de los derechos» (De l'esprit des droits et de leur relativité: théorie dite de l'abus de droit), en Del abuso del Derecho y otros ensayos, Temis, Bogotá, 1982.

Kant, I., Fundamentación de la Metafísica de las Costumbres (ed. bilingüe), Ariel, Barcelona, 1999.

Kaufman, Y., The Religion of Israel, trans. Moshe Greenberg, Schocken Books, New York, 1972.

LA Touche, F., «Plato's doctrine of participation», Hermathema, n 59 (May, 1942), pp. 6-19.

Laski, H.J., The American Democracy: A Commentary and An Interpretation, Viking Press, New York, 1948.

LEWIS, C.S., Screwtape Letters, Harper Collins, New York, 2000.

LEWIS, J.S., Mining the sky: untold riches from the asteroids, comets, and planets, Addison-Weasley Publishers, Reading Mass, 1996.

LiPTON, M.., «Business: Those guns for hire», Time Magazine (Jan 29, 1979). 
Lohmann, L., «Performative Equations and Neoliberal Commodification: The Case of Climate», en B. Büscher et al. (ed.), Nature Inc.: Environmental Conservation in the Neoliberal Age, University of Arizona Press, Tucson, 2014.

LozANO Villegas, G.., «Libre desarrollo de la personalidad y cambio de sexo: el transexualismo», en IV Fornadas de Derecho Constitucional y Administrativo, Universidad Externado de Colombia, Bogotá, 2003, pp. 217-240.

Martínez Doral, J.M., La estructura del conocimiento jurídico, Eunsa, Pamplona, 1963.

Massini, C.I., Filosofía del Derecho. Vol. 1. El derecho natural y los derechos bumanos, Lexis-Nexis, Buenos Aires, 2005.

Menand, L., Metaphysical Club, Macmillan, New York, 2002.

Mora Calvo, H.R., «El hombre en Santo Tomás de Aquino», Revista de filosofía de la Universidad de Costa Rica, XXXIII. n. 80 (1995), pp. 87-94.

Nafarrete Susaeta, A., «Los fundamentos de la unicidad del ser y la cognoscibilidad de Dios en Juan Duns Escoto», Anuario de Historia de la Iglesia, vol. X (2001), pp. 489-495.

PATTESON, R., «Plato's theory of participation: platonic forms and the making sense objects», The Society for Ancient Greek Philosophy Newsletter, 23 (1980).

RABBI-BALDI, R., «El concepto de Derecho en el realismo clásico a partir de las opiniones de Michel Villey y Georges Kalinowski», Persona y derecho, no 25 (1991), pp. 73-114.

- «La experimentación en seres humano. Reflexiones a partir del nuevo Código Civil y Comercial de la Argentina», en R. Rabbi-Baldi (coord.), Los derechos de la persona en el nuevo Código Civil y Comercial. Aproximación a algunos aspectos novedosos, Universidad de Buenos Aires, Thomson Reuters-La Ley, Buenos Aires, 2017, pp. 95-11

RABBI-BALDI, R. y LAISE, L., «Una mirada filosófica a la centralidad de la persona en el Nuevo Código Civil y Comercial de la Nación Argentina», en R. RabbiBaldi (coord.), Los derechos de la persona en el nuevo Código Civil y Comercial. Aproximación a algunos aspectos novedosos, Universidad de Buenos Aires, Thomson Reuters-La Ley, Buenos Aires, 2017.

RAMACHANDRAN, G., «Against the Right to Bodily Integrity: Of Cyborgs and Human Rights», Denver University Law Review (2009), 87.

Rodríguez-Molinero, M., «La doctrina del derecho natural de Hugo Grocio en los albores del pensamiento moderno», Persona y Derecho, vol. 26 (1992), pp. 291-305

Rizha, J., Perfecting Human Actions: St. Thomas Aquinas on buman participation on Eternal Law, The Catholic University of America Press, Washington D.C., 2009.

SARTrE, J.P., El existencialismo es un humanismo, Unam, México, 2006.

SEAGRave, S.A., The Foundations of Natura Morality. On the Compatibility of Natural Rights and the Natural Law, University of Chicago Press, Chicago, 2014.

ScHOuppe, J.P., Le realisme juridique, Story-Scientia, Bruxelles, 1987. 
TALISse, R., Democracy and Moral conflict, Cambridge University Press, Cambridge, 2005.

Tiesen, A., «Should Human Life be Considered as Property?», Central Law fournal, vol. 79 (1914).

Tomás De Aquino, De principiis Naturae, Société Philosophique, Friburgo, 1950.

- Ente et Essentia, Herder, Freiburg, 2007.

- Suma de Teología, Biblioteca de Autores Cristianos, Madrid, 1997.

Van Mill, D., Deliberation. Social Choice and Absolutist Democracy, Routledge, London-New York, 2006.

YounG, S., «Trans women could get pregnant 'tomorrow', fertility professor claims», The Independent, en https://www.independent.co.uk/life-style/menpregnant-womb-transplant-dr-richard-paulson-transgender-a8037201.html

\section{Sentencias}

Corte Constitucional Colombiana, Sentencia, T-918-12. M.P. Jorge Iván Palacio Palacio.

Corte Constitucional Colombiana, Sentencia T-771/13, M.P. María Victoria Calle Correa.

«Norsworthy v. Beard», United States District Court; Northern Disctrict of California, April 2, 2015.

. Kass v. Kass, 235 A.D.2d 150 (N.Y. App. Div. 1997).

High Court of Justice, A, D and G v N-W Lancashire Health Authority (Reino Unido).

Sunstrom v. Frank, United States District Court for the Eastern District of Wisconsin. January 27, 2007). (Estados Unidos).

JCivComConciliacionyFamiliaVillaDolores, C. J. A. y otra - solicitan autorización, LLC2007 (noviembre), 1102 (Argentina).

C. Pardo Schlesinger, Salvamento Parcial y aclaración de voto a la sentencia T-423 de 2017 de la Corte Constitucional (Colombia).

CSJN, «Bahamondez, Marcelo s/ medida cautelar», Fallos 316:479 (1993), consid. 12 del voto concurrente con la mayoría de los jueces Barra y Fayt, luego reiterado, entre otros, en Fallos 323:3229 y 327:3753 (Argentina). 
RECENSIONES 
